\title{
METÁFORAS ONLINE \\ AS CONCEITUALIZAÇÕES DE APRENDIZES UNIVERSITÁRIOS DE INGLÊS SOBRE APRENDIZAGEM À DISTÂNCIA
}

\author{
Ronaldo Corrêa Gomes Junior é professor de Língua Inglesa do Instituto Federal de Minas Gerais (Campus Ouro Preto) e \\ doutorando em Linguística Aplicada pela Universidade Federal de Minas Gerais. \\ E-mail: ronaldocgomes@gmail.com
}

Resumo

Este trabalho investigou as metáforas de estudantes universitários sobre a aprendizagem de inglês à distância. Os dados revelam que esta é vista como um recurso facilitador capaz de resignificar as noções de tempo e espaço.

\begin{abstract}
This work investigated university students' metaphors about English distance learning. The data reveal that it is seen as a facilitator resource capable of reframing the notions of time and space.
\end{abstract}

\section{1) Introdução}

De acordo com Lakoff e Johnson (1980), em Metaphors We Live By, nosso pensamento é governado por conceitos, não sendo estes somente questões do intelecto. Esses conceitos governam também o funcionamento diário, estruturam a percepção humana, influenciam o agir dos indivíduos no mundo, bem como o relacionamento deles. Dessa forma, os autores afirmam que o sistema conceitual tem um papel fundamental na definição das realidades diárias humanas. Sobre essa questão, os autores fazem a seguinte proposição: "Se estamos certos em sugerir que o nosso sistema conceitual é amplamente metafórico, então, a maneira que pensamos, o que experienciamos e fazemos diariamente é muito mais uma questão de metáfora" (Lakoff e Johnson, 1980, p. 3).

Segundo a Teoria Cognitiva da Metáfora, as metáforas estão localizadas na mente. Embora sejam percebidas na linguagem, elas são utilizadas (ditas ou expressas), pois estão em nossa mente estruturando o pensamento. Dessa forma, para Berber Sardinha (2007, p.16), investigar metáforas é um meio efetivo de investigar o pensamento e a mente humana. $\mathrm{O}$ autor elenca algumas razões para se estudar metáfora: (a) compreender como as pessoas conceitualizam o mundo; (b) interpretar as mensagens de grupos sociais e ideologias; (c) entender as conceitualizações humanas como um produto individual e sócio-histórico; (d) entender estilos de diversos tipos de discursos; e (e) analisar tudo isso através da linguagem.

A pesquisa relatada neste artigo pretendeu investigar as conceitualizações de aprendizes universitários sobre a aprendizagem de inglês por meio de uma análise de suas metáforas. Para isso, foram analisadas as metáforas de aprendizes universitários de inglês obtidas por meio de uma atividade de reflexão sob a luz das teorias de Lakoff e Johnson (1980) e Fauconnier e Turner (2002).

Em Mental Spaces, Fauconnier (1994, p.xviii) afirma que comumente se acredita que o sentido está nas palavras. No entanto, as palavras são apenas "a ponta do iceberg", estando o sentido e muitas outras concepções "escondidas" em nossa mente. Em The Way We Think, Fauconnier e Turner (2002) afirmam que o pensamento metafórico opera na cognição, mostrando estruturas uniformes e princípios dinâmicos, sejam eles espetaculares e notáveis ou convencionais e comuns. As operações mentais ocorridas 
durante o processamento metafórico acontecem na "velocidade da luz" (p.18) e são altamente imaginativas, produzindo assim consciência de identidade, igualdade e diferença. Pesquisar metáforas, portanto, é compreender como funciona o pensamento humano por meio da linguagem, é acessar a ponta do iceberg e o resultado de muito do que se encontra "submerso".

Sendo assim, a análise metafórica foi escolhida por se configurar como uma excelente ferramenta metodológica para acessar os conceitos dos aprendizes sobre o que é aprender inglês. Além disso, esse é um tipo de análise indireta, ou seja, ao invés de perguntar diretamente como os aprendizes percebem a aprendizagem, estimula-se a formulação de metáforas. É a partir delas que o pesquisador, indireta e indutivamente, perceberá como os aprendizes realmente enxergam o processo.

$\mathrm{Na}$ Linguística Aplicada, as metáforas começaram a ser utilizadas em pesquisas com o objetivo de descobrir o que os alunos acreditam e pensam sobre assuntos referentes ao processo de ensino-aprendizagem de línguas (Block, 1992; Swales, 1994; Ellis, 2001; Kramsch, 2003). Essas pesquisas nos mostram que as metáforas produzidas por aprendizes são ótimos veículos para deixar claras ideias e concepções. Sendo assim, analisar metáforas seria como encarar o processo de aprendizagem pela perspectiva do participante.

Considerando, então, a importância da investigação das concepções dos alunos, juntamente com a característica cognitiva e reveladora das metáforas, esta pesquisa teve como objetivo identificar as metáforas sobre aprendizagem online, relacionadas ao processo de aprendizagem de inglês, de alunos universitários de diversos cursos de graduação da Universidade Federal de Minas Gerais, que cursavam disciplinas de Inglês Instrumental.

\section{2) A Teoria da Metáfora Conceitual}

De acordo com Schröder (2008), embora o caráter cotidiano das metáforas já tivesse sido mencionado na filosofia, linguística e psicologia - nas abordagens de Locke, Vico, Kant, Buhler, Blumberg e Weinrich - foi somente no início da década de 80 com a aclamada obra Metaphors we live by, que a característica cotidiana e cognitiva da metáfora adquiriu popularidade e visibilidade. O referido livro, escrito por Lakoff e Johnson (1980), revolucionou muitos conceitos da Linguística, principalmente pela crítica ao objetivismo e por levar em consideração as bases experienciais humanas. Nessa visão, muitas concepções da tradição linguístico-ocidental começaram a ser repensadas, como as de significado, conceitualização, razão, conhecimento, verdade e, principalmente, a de linguagem (Ferrari, 2005).

Do ponto de vista da cognição, entender a linguagem humana é compreender a rede complexa que a constitui, é perceber a linguagem valorizando as experiências corporais do ser humano, devido a sua importância na estruturação do pensamento. Nesse sentido, de acordo com os autores, o pensamento seria estruturado por meio de processos metafóricos.

A partir dos estudos de Lakoff e Johnson (1980), surgiram muitas publicações na área que fugiam da visão das metáforas como sendo apenas um recurso estilístico. $\mathrm{Na}$ perspectiva da Teoria da Metáfora Conceitual, as metáforas não são de caráter exclusivamente linguístico, mas também da cognição humana. Para Lakoff e Johnson (1999, p.45), "a metáfora conceitual é presente tanto no pensamento quanto na linguagem. É difícil pensar em uma experiência subjetiva comum que não seja convencionalmente conceitualizada em termos de metáfora". 
Ao contrário das teorias tradicionais, que levavam em consideração somente a língua, a Teoria da Metáfora Conceitual passou, observando evidências do dia a dia, a dar relevância também a processos linguístico-cognitivos mais complexos.

De acordo com Berber Sardinha (2007), essa teoria se opõe à visão lógicopositivista por propor que não há verdades absolutas, haja vista que as metáforas são culturalmente mapeadas de acordo com as ideologias e valores de uma sociedade. A metáfora seria mental, cognitiva e abstrata, e se manifestaria em expressões metafóricas na fala e na escrita. Assim, de acordo com Lakoff e Johnson (1980), o que constitui a metáfora não é uma palavra ou expressão específica, mas o mapeamento entre dois domínios, o alvo e o fonte.

Ao caracterizar a Teoria da Metáfora Conceitual, Berber Sardinha (2007) menciona as noções de metáfora conceitual e metáforas linguísticas: uma metáfora conceitual é a conceitualização e as metáforas linguísticas seriam as realizações de uma metáfora conceitual. As metáforas conceituais são inconscientes e, como não são usadas para embelezar e enfeitar um texto, na maioria das vezes, são confundidas com o senso comum. As expressões metafóricas seriam então motivadas por metáforas conceituais. Pelo fato de serem culturais e refletirem crenças e valores, não podemos criar metáforas conceituais, já que se tentássemos, provavelmente elas não seriam compartilhadas por uma sociedade.

Lakoff e Johnson (1980, p.5) afirmam que, ao contrário do que muitos pensam, "as metáforas estão presentes no dia a dia não só na linguagem, mas nos pensamentos e ações humanas". De acordo com Ellis (2001), a teoria de Lakoff e Johnson se fundamenta em basicamente dois princípios: de que a metáfora está longe de ser um artefato artificial e rebuscado e de que elas não são questões somente de linguagem, mas de pensamento.

Tecnicamente falando, o processo metafórico está ligado à projeção entre um domínio fonte com o domínio alvo. Por exemplo, na metáfora O AMOR É UMA VIAGEM, há a projeção entre o domínio fonte (uma viagem) no domínio alvo (o amor). Dessa forma, o que constitui o significado da metáfora, não é a expressão em si, mas o mapeamento entre os dois domínios em questão. Representando essa expressão graficamente, temos o seguinte esquema:

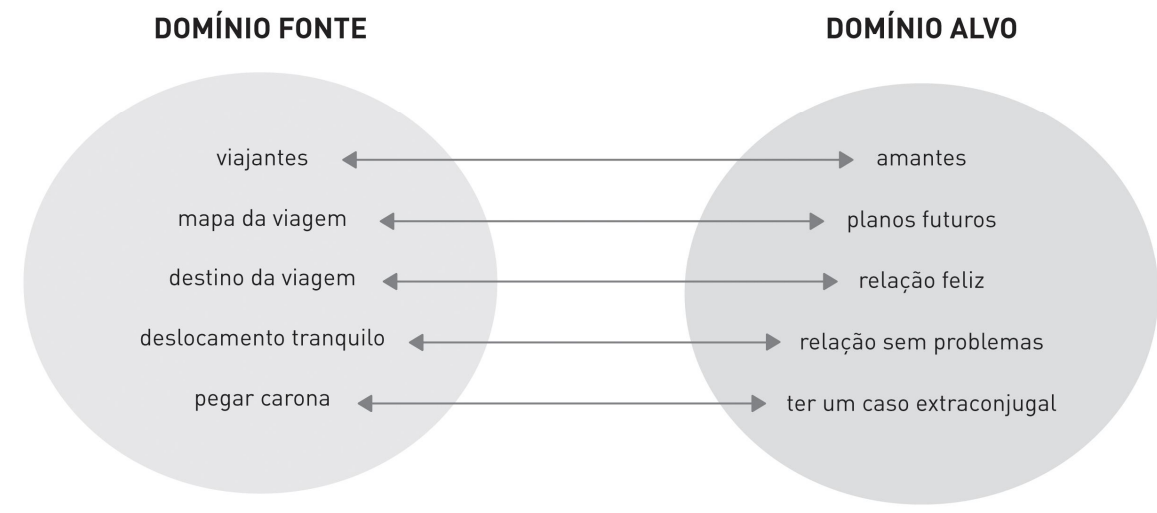

Figura 1 - Diagrama da Teoria da Metáfora Conceitual (Sardinha, 2007, p.31) 
Para Kövecses (2002), a metáfora conceitual consiste na interação entre dois domínios, em que um domínio é entendido em termos de outro. $\mathrm{O}$ autor define domínios como quaisquer organizações coerentes de experiência (Kövecses, 2002, p. 4).

\section{3) A Teoria da Mesclagem Conceitual}

Para Fauconnier e Turner (2002), a Mesclagem Conceitual é uma operação mental básica, altamente imaginativa e crucial para os mais simples tipos de pensamento (p.18). Nessa perspectiva, a mesclagem seria uma atividade inconsciente, invisível e entrincheirada em todos os aspectos da vida humana. De acordo com Rocha (2006), a mesclagem é uma operação cognitiva na qual pelo menos dois domínios distintos são integrados em um outro domínio com estruturas emergentes características. Como afirma Fauconnier (2001), a Integração Conceitual (Mesclagem) tem um papel fundamental na construção de sentido cotidiana; nas artes e ciências, no desenvolvimento tecnológico, bem como nos diversos tipos de pensamentos.

Neste processo, o Espaço Mescla surge do mapeamento entre Espaços Mentais. Segundo Fauconnier e Turner (2002), Espaços Mentais são pequenos pacotes conceituais que são construídos na medida em que se pensa ou fala, com o propósito de entendimento local e ação. Para os referidos autores (1998), Espaços Mentais são parciais e estruturados por frames e modelos cognitivos. Eles são interconectados, podem ser modificados na medida em que o pensamento e o discurso se desdobram e podem ser utilizados para modelar mapeamentos dinâmicos no pensamento e na linguagem.

Em entrevista à Coscarelli (2005), Fauconnier define Espaços Mentais como prováveis ativações estabelecidas no cérebro, mais especificamente na memória de trabalho, que provavelmente seriam ligadas e conectadas por ativações neuronais (p.291). Grady et al. (1999) diferem Espaços Mentais da noção de domínios (Lakoff e Johnson, 1980) afirmando que:

Na Teoria da Mesclagem, a unidade básica da organização cognitiva não é o domínio, mas o 'espaço mental' (Fauconnier, 1994[1985]), uma estrutura representacional parcial e temporária que os falantes constroem ao pensar e falar sobre situações percebidas, imaginadas, passadas, presentes ou futuras. Espaços Mentais (ou 'espaços', abreviadamente) não são equivalentes a domínios, mas dependem deles: espaços representam cenários particulares que são estruturados por domínios dados. (Grady, 199, p. 2)

Para Fauconnier e Turner (1998, 2002), a mesclagem possui os seguintes elementos:

- Espaços Input: Espaços que contém estruturas parciais que serão integrados (mesclados).

- Espaço Genérico: Espaço que possui características comuns aos dois Espaços Input 1 e 2. 
- Espaço Mescla: Um quarto Espaço Mental que surge da integração dos dois Espaços Input.

- Estrutura Emergente: Estrutura que emerge do Espaço Mescla e não está nos Espaços Input.

- Projeção seletiva: Nem todos os elementos e estruturas dos Espaços Input são projetados no Espaço Mescla.

- Composição: A Mesclagem pode ser composta de elementos dos Espaços Input para fornecer relações que não existem nos Espaços Input separadamente. Esse tipo de projeção também é chamado de fusão.

- Complemento: Processo que envolve o recrutamento de uma grande variedade de conhecimentos prévios (ausentes nos Espaços Input) para a construção do Espaço Mescla.

- Elaboração: Recrutamento e desenvolvimento de novas estruturas para o Espaço Mescla baseadas em princípios imaginativos e efetivamente ilimitados. A elaboração desenvolve a mescla através de simulações mentais imaginativas de acordo com princípios e lógicas próprias ao Espaço Mescla.

Sendo assim, a construção de uma rede de integração (Fauconnier e Turner, 2002) envolve a criação de Espaços Mentais, o mapeamento entre espaços, a projeção seletiva para a mesclagem, a localização de estruturas compartilhadas, a projeção de volta aos Espaços Input, o recrutamento de novas estruturas para os Espaços Input ou para o Espaço Mescla, e a execução de várias outras operações no Espaço Mescla em si (p.44). Os autores representam o modelo de Integração Conceitual através do seguinte diagrama:

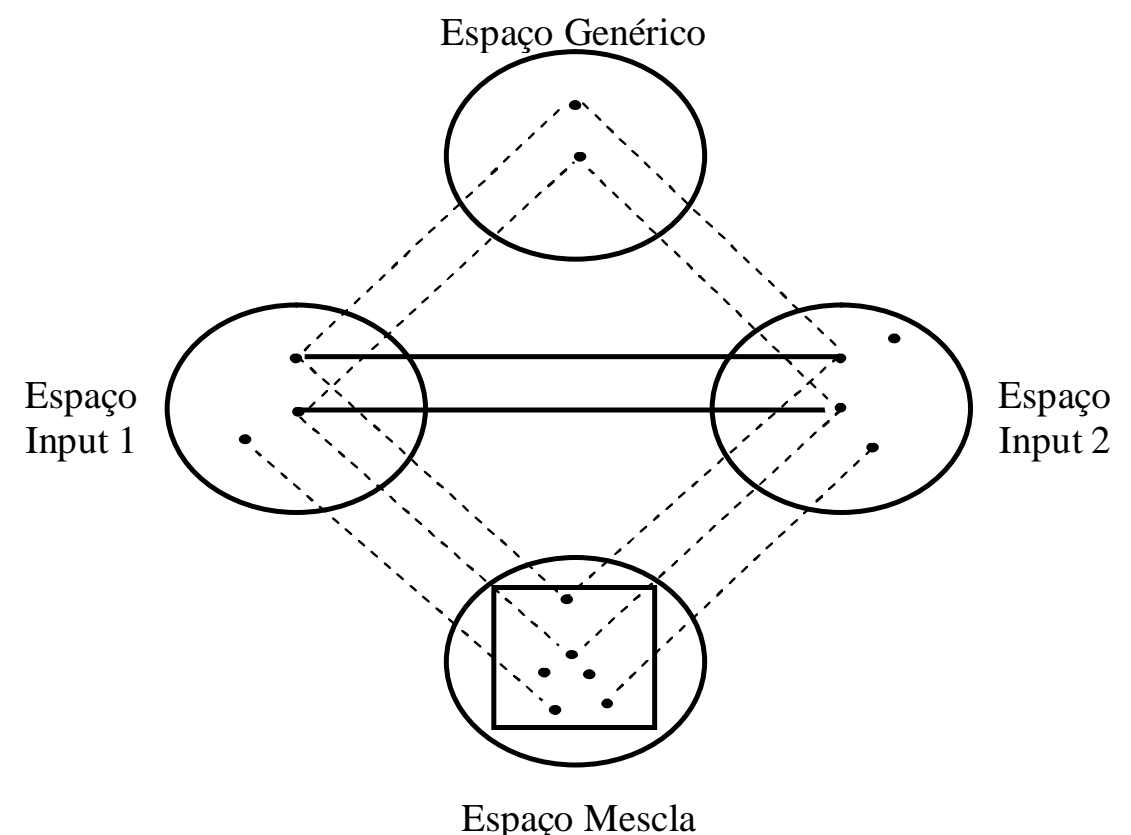

Figura 2 - O Diagrama Básico da Teoria da Mesclagem Conceitual (Fauconnier, 2002, p.46). 
A essência dessa operação é a construção de um mapeamento parcial entre espaços mentais e a projeção seletiva desses inputs em um espaço mental mesclado. (Fauconnier, 2001).

Para ilustrar uma rede de integração, analisemos a seguinte situação: $O$ estudante diz para o professor: "O senhor vai cometer um holocausto com esse teste". Podemos dispor esta mesclagem da seguinte forma:

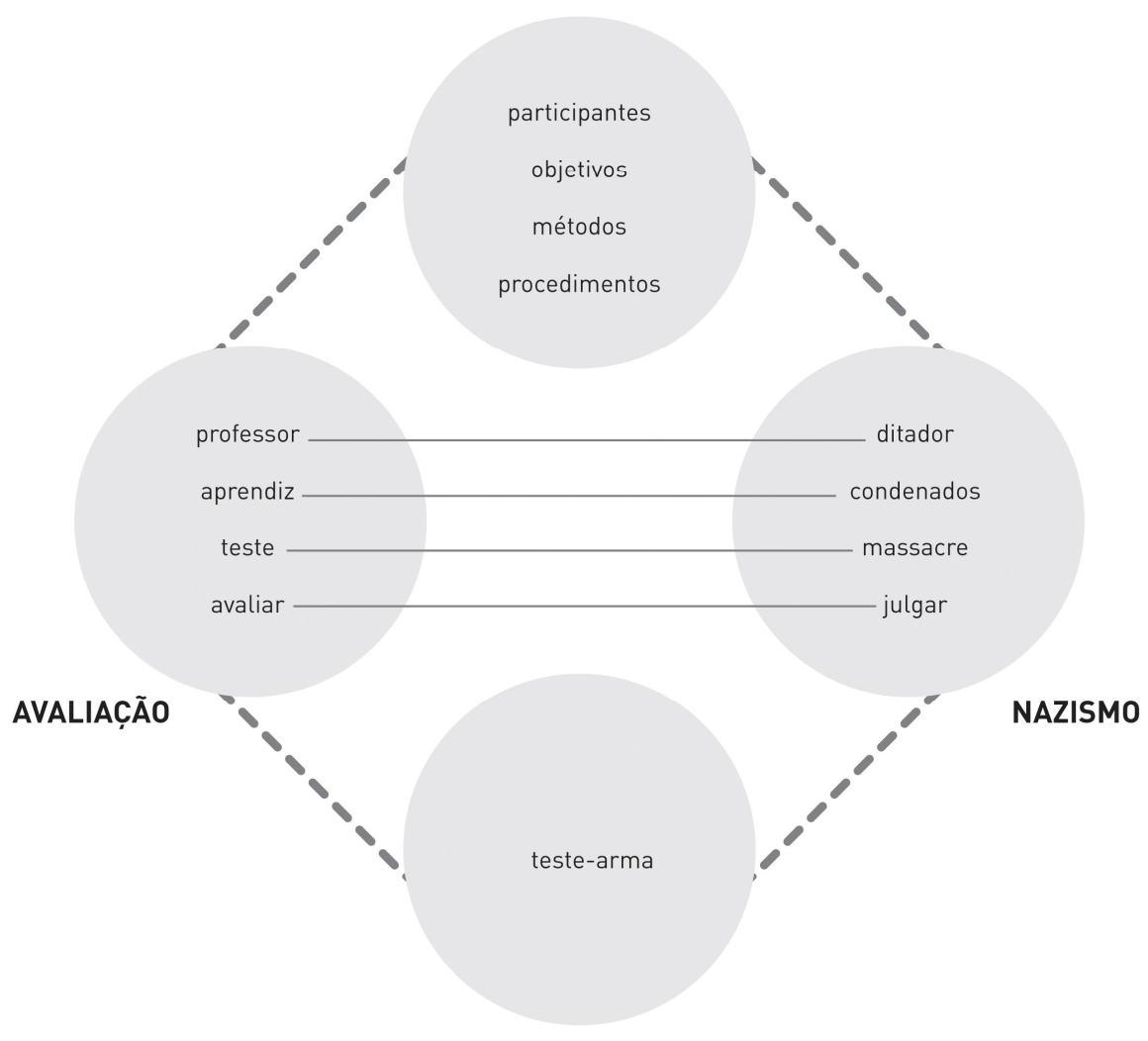

Figura 3 - Exemplo de uma Rede de Integração

$\mathrm{Na}$ rede de integração apresentada, temos o mapeamento entre os Espaços Input Avaliação e Nazismo. O professor é mapeado no domínio de um ditador, o aprendiz no de um condenado, o teste no de um massacre e avaliar em julgar. Sendo assim, temos o Espaço Input 1 (professor, aprendiz, teste e avaliar), o Espaço Input 2 (ditador, condenado, massacre e julgar), o Espaço Genérico (participante, objetivos, métodos e procedimentos) e a Mesclagem, na qual a Estrutura Emergente é um teste que é tão poderoso quanto uma arma, chegando ao ponto de causar um holocausto.

\section{4) A Pesquisa}

Este artigo é um recorte de uma pesquisa de mestrado, cujo objetivo era investigar metáforas sobre vários aspectos relacionados ao processo de ensino e aprendizagem de inglês. Este estudo se configurou como uma pesquisa de levantamento de opinião (survey research) de natureza mista, ou seja, com abordagens quantitativas e 
qualitativas. Em um primeiro momento, foram coletados, através de uma atividade de reflexão, relatos que permitiram entender como os estudantes da UFMG conceitualizavam seus processos de aprendizagem de inglês. Posteriormente, foram feitas as análises quantitativas e qualitativas.

Segundo Johnson (1992), o propósito de uma pesquisa de opinião é compreender características em um grupo de interesse inteiro (uma população) através da análise de um subconjunto deste grupo (uma amostra). No caso desta pesquisa, pretendeu-se compreender como os estudantes universitários da UFMG (a população) conceitualizam a aprendizagem online por meio da análise de subconjuntos (as amostras). Geralmente, uma pesquisa de opinião é definida como um estudo de um grande grupo através do estudo de um subconjunto deste.

De acordo com Dörnyei (2007), nos últimos 15 (quinze) anos, pesquisas de métodos mistos tem sido crescentemente vistas como uma terceira abordagem metodológica. O autor cita Strauss e Corbin (1998, p.34), que ilustram essa terceira abordagem da seguinte maneira:

\footnotetext{
Ambas as formas de pesquisa qualitativas e quantitativas tem papéis a serem cumpridos na formulação de teorias. A questão não é se usar ou não uma forma ou outra, mas como elas funcionarão juntas a fim de fomentar o desenvolvimento da teoria.
}

Os referidos autores citados por Dörnyei (2007) acreditam que as duas abordagens devem ser utilizadas de forma complementar, de maneira que o qualitativo interaja com o quantitativo, e vice-versa. O qualitativo deve direcionar o quantitativo e o quantitativo responder ao qualitativo, em um processo circular e evolutivo, de maneira que as especificidades de cada abordagem contribuam juntas para o desenvolvimento da pesquisa. Seliger e Sohamy (1989) caracterizam como ecléticas (p.114) as pesquisas que livremente combinam elementos de diferentes tipos de abordagens de pesquisa.

Os dados foram coletados dentro do Projeto IngRede. De acordo com Paiva et al. (2009), o projeto IngRede surgiu como uma necessidade das universidades federais de oferecer disciplinas de leitura em língua inglesa para toda a comunidade acadêmica. O projeto, através de uma abordagem colaborativa, busca atender a todos os estudantes, oferecendo conhecimentos instrumentais sobre como ler e compreender um texto em inglês.

O projeto foi idealizado em 1999 em um evento sobre educação à distância em que a pauta principal de muitas das conversas era a grande demanda por aulas de leitura em língua inglesa, bem como o grande obstáculo da falta de professores que ainda enfrentam as universidades públicas no Brasil. Dessa forma, um grupo de professores, liderados pela Profa. Vera Menezes, decidiu que iria criar um curso de leitura mediado pelo computador, que seria difundido e adaptado em várias universidades.

Esse grupo foi aumentando e, consequentemente, foi fundado o IngRede - um projeto de ensino e pesquisa sobre aprendizagem de leitura em inglês em ambiente virtual (PAIVA et al., 2009). Esse projeto foi desenvolvido graças a uma parceria entre 10 (dez) universidades federais brasileiras (UFG, UFMG, UFMT, UFRJ, UFSJ, UFSM, UFU, UFJF, UFPA e UFPEL). Na UFMG, o projeto foi desenvolvido com o apoio da Pró-Reitoria de Graduação e do projeto REUNI (Reestruturação e Expansão das Universidades Federais) e implementado pela Profa. Junia Braga. Foi produzido um $\mathrm{CD}-\mathrm{ROM}$ e as atividades didáticas foram inseridas na Plataforma Moodle. 
O Projeto IngRede é composto de duas disciplinas online de Inglês Instrumental. O curso "UNI001 - Inglês Instrumental I" busca desenvolver a habilidade de leitura de diversos gêneros textuais escritos em língua inglesa. O principal objetivo da disciplina é contemplar as estratégias de leitura e trabalhar com a compreensão geral e a busca de informações específicas. Ademais, as unidades e atividades a serem trabalhadas contêm elementos linguísticos necessários para o entendimento de um texto tanto em contexto geral como na área de interesse do aprendiz.

A disciplina "UNI002 - Inglês Instrumental II" busca o aperfeiçoamento da habilidade de leitura de diversos gêneros textuais (acadêmicos e não-acadêmicos) em língua inglesa. Ao automatizar o uso das estratégias de leitura trabalhadas na disciplina anterior, promove uma compreensão mais rápida e eficiente dos textos. Além disso, contempla aspectos discursivos e linguísticos importantes para a compreensão de textos.

Dessa forma, os participantes desta pesquisa foram os estudantes matriculados nas duas disciplinas anteriormente mencionadas. Tendo esses participantes como sujeitos dessa pesquisa, pôde-se ter uma visão de todas as áreas do conhecimento, haja vista a diversidade do público que a disciplina atende. No segundo semestre de 2009 , a disciplina UNI001 - Inglês Instrumental I possuía 1.388 estudantes e a UNI 002 Inglês Instrumental II possuía 891, totalizando 2.279 estudantes de diversos cursos de graduação.

O projeto IngRede atende estudantes de todas as áreas (Ciências Exatas, Humanas, Biológicas, Agrárias etc). Sendo assim, esse grupo de participantes foi escolhido por atender fielmente aos objetivos e perguntas dessa pesquisa e por, possivelmente, ilustrar como pensam os estudantes da UFMG. Dos 2.279 estudantes, somente $341(15 \%)$ realizaram a atividade de reflexão.

$\mathrm{Na}$ atividade de reflexão proposta aos alunos das duas turmas, foi pedido que os mesmos completassem algumas frases sobre o processo de aprendizagem de língua inglesa com o objetivo de encontrar metáforas sobre o tema. No instrumento havia instruções a serem seguidas pelos participantes para completar as afirmativas propostas com alguma frase, expressão ou metáfora que melhor caracterizasse seu pensamento sobre o assunto. A atividade foi criada no GoogleDocs e postada no Ambiente Virtual de Aprendizagem (AVA) das disciplinas anteriormente citadas. A atividade pode ser acessada pelo seguinte endereço eletrônico: http://spreadsheets.google.com/viewform?formkey=dGhmMnJKMUx0bThleEpHNjIx MWtobFE6MA.

O instrumento foi adaptado e inspirado em Kramsch (2003). No original, os participantes deveriam completar as seguintes frases: "Aprender Inglês é como...", "Falar Inglês é como..." e "Escrever em Inglês é como...". Ao adaptar o questionário para esta pesquisa, foram inseridas as seguintes frases: "Aprender inglês é como...", "Saber Inglês é como...", "Não saber inglês é como...", "Aprender inglês à distância é como...".

A análise dos dados seguiu os parâmetros e procedimentos da pesquisa quantitativa e qualitativa (Holiday, 2002; Dörniey, 2007).

$\mathrm{Na}$ primeira fase de análise, os dados foram lidos várias vezes e foram destacados somente os excertos que continham expressões metafóricas. Em seguida, os dados foram analisados de maneira que fosse possível encontrar unidades significativas (Holiday, 2002) capazes de apontar as conceitualizações dos estudantes sobre o processo de aprendizagem. Dessa forma, as expressões encontradas foram analisadas e separadas em dois grandes grupos: Metáforas de Esquemas Imagéticos e Metáforas 
Estruturais. Em cada grande grupo, as expressões foram categorizadas contextualmente de acordo com a regularidade dos domínios.

Dos 2.279 alunos da disciplina, somente 341 realizaram a atividade de reflexão. Em porcentagem, isso significa que a amostra obtida representa $14,96 \%$ da população. Foram utilizadas somente as expressões metafóricas significativamente regulares, ou seja, aquelas que eram comuns e poderiam caracterizar a amostra em questão.

Neste artigo serão analisadas as metáforas sobre o último item da atividade: aprender inglês à distância.

\section{5) As metáforas}

Das 341 respostas, apenas 46 eram expressões metafóricas significativamente regulares, o que representa $13 \%$ do total de respostas. Das 46 expressões encontradas, $75 \%$ eram metáforas estruturais, $9 \%$ eram metáforas de esquemas imagéticos e $16 \%$ eram expressões idiomáticas formadas por metáforas.

As expressões metafóricas relacionadas à aprendizagem online, em sua maioria, referem-se à mobilidade no espaço. Outros aspectos enfatizados são a praticidade e as facilidades resultantes da adição da Internet à aprendizagem da língua. Abaixo, segue uma nuvem de palavras, com os vocábulos mais encontrados nos dados.

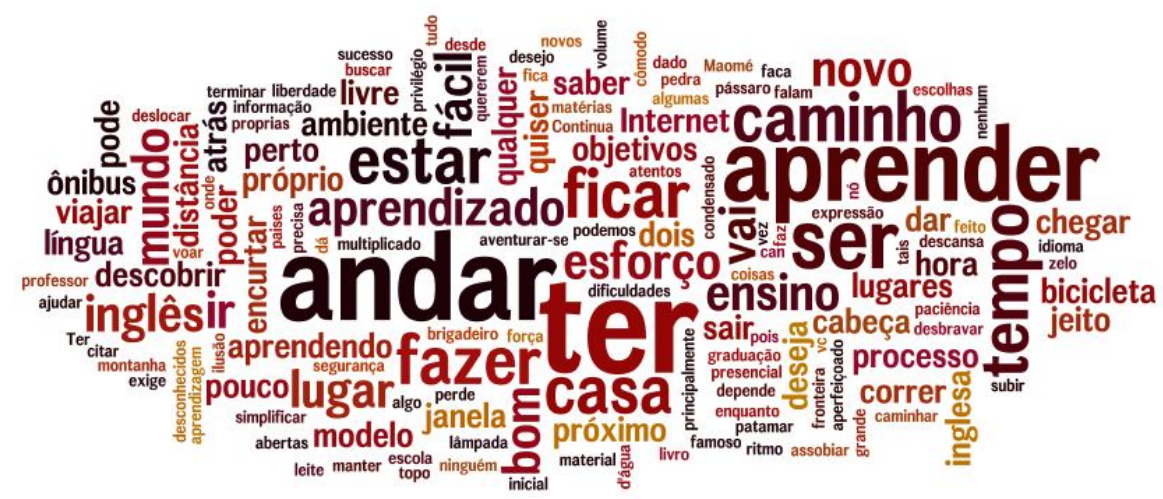

Figura 4 - Nuvem de palavras de APRENDER INGLÊS À DISTÂNCIA É COMO...

Como se pode observar na figura, quanto maior é a imagem da palavra, mais vezes ela foi encontrada. Sendo assim, por meio dessa lista de frequência em forma de ilustração, é possível perceber que para esses participantes, a aprendizagem online parece afetar seus limites espaciais e meios de locomoção.

A maioria das metáforas menciona a questão da mobilidade espacial relacionada à aprendizagem à distância. Um esquema imagético presente nessas metáforas é o esquema PERTO/LONGE (NEAR/FAR), o que representa 9\% das metáforas regulares. Abaixo, seguem as expressões metafóricas agrupadas nessa categoria:

\begin{tabular}{|c|}
\hline APRENDER INGLÊS À DISTÂACIA É COMO ESTAR \\
PERTO OU LONGE - 9\% \\
\hline $1 . \quad$... aprender inglês de perto. Só depende de você. (Pe22-BIO) \\
\hline
\end{tabular}


2. ... ficar mais próximo da língua inglesa (Lu21-NUT)

3. ... estar distante, mas ao mesmo tempo perto, do processo de aprendizado permitido pelo poder de expressão da Internet. $\mathrm{O}$ ensino à distância não perde em nada do ensino presencial, já que estamos aprendendo do mesmo jeito sem as diversas restrições impostas pelo ambiente. (Du20-CIC)

4. ...correr atrás de seus objetivos. (Lu20-GSS)

Quadro 1 - Aprender inglês à distância é como estar perto ou longe

Nas expressões 1 e 2, os aprendizes afirmam que aprender inglês online é estar mais próximo da língua. Em outras palavras, a aprendizagem à distância possibilitaria um contato maior com a língua inglesa. Destaco aqui a metáfora 4 , em que há a presença da expressão "correr atrás", popularmente conhecida e utilizada para designar o ato de persistir e ir em busca de seus objetivos.

Em relação às metáforas estruturais, assim como no tema anterior, os aprendizes conseguiriam se (loco)mover no espaço por meio da aprendizagem da língua. Essas metáforas foram bastante recorrentes com relação a esse tema e geraram uma grande categoria com quatro subcategorias. Abaixo, segue a representação gráfica da categoria APRENDER INGLÊS À DISTÂNCIA É COMO LOCOMOVER-SE NO ESPAÇO, juntamente com suas quatro subcategorias.

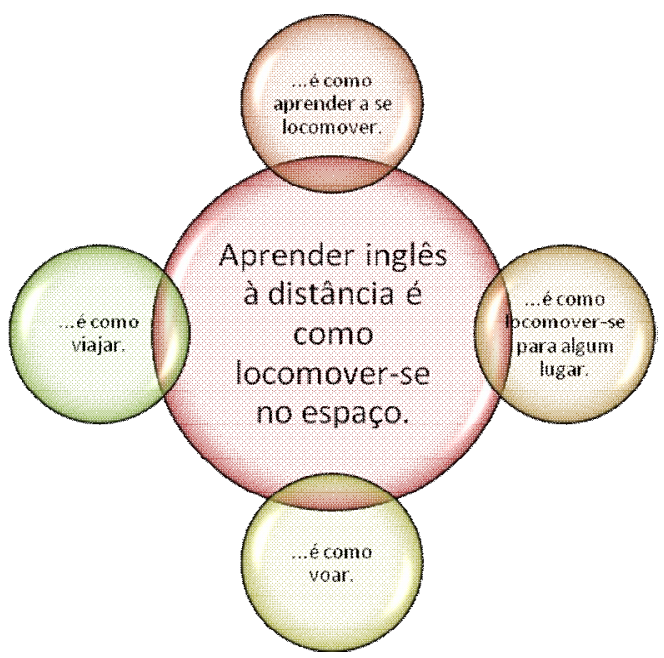

Figura 5 - Aprender inglês à distância é como locomover-se no espaço

A primeira subcategoria refere-se especificamente à locomoção no espaço. Vinte e um por cento das expressões significativamente regulares apontam a aprendizagem online como possibilitadora de locomoção no espaço. Nas metáforas estruturais, a locomoção no espaço também é utilizada como domínio fonte para a aprendizagem à distância. É por meio dela que os aprendizes conseguiriam deslocar-se espacialmente. No quadro abaixo, estão as expressões metafóricas da subcategoria APRENDER INGLÊS À DISTÂNCIA É COMO LOCOMOVER-SE PARA ALGUM LUGAR. 


\begin{tabular}{|c|}
\hline $\begin{array}{l}\text { APRENDER INGLÊS À DISTÂNCIA É COMO LOCOMOVER-SE PARA } \\
\text { ALGUM LUGAR - 21\% }\end{array}$ \\
\hline $\begin{array}{l}\text { 1. ... andar pelo países que falam Inglês. Te faz chegar a um alto patamar sem ter } \\
\text { que se deslocar a nenhum lugar. (Ma26-ADM) } \\
\text { 2. ... andar para todo mundo. (Xx25-MED) }\end{array}$ \\
\hline $\begin{array}{l}\text { 3. ... andar de ônibus, não só na janela, mas com uma gostosa do seu lado!!! } \\
\text { (Ra22-MED) } \\
\text { 4. ... entrar em um ônibus e se sentar na janela. (Ev23-FIS) }\end{array}$ \\
\hline $\begin{array}{l}5 . \text {... estar em dois lugares ao mesmo tempo. (St23-FIS) } \\
6 . \quad \text {... ir a escola sem sair de casa. (Ja23-CCO) }\end{array}$ \\
\hline $\begin{array}{l}\text { 7. ... estar livre para navegar quando quiser e quando puder. (Cr23-EMC) } \\
\text { 8. ... tomar as rédeas do seu próprio aprendizado e dizer "Yes, I can!" (Na21- } \\
\text { BIO) } \\
\text { 9. ... subir no topo sem escada. (Ci24-ECO) }\end{array}$ \\
\hline
\end{tabular}

Quadro 2 - Aprender inglês à distância é como locomover-se para algum lugar

Nas metáforas 1 e 2, a aprendizagem online é percebida como um meio de se locomover para outros países. Em outras palavras, a aprendizagem online seria uma forma de conseguir ultrapassar as barreiras físicas e geográficas. Já as metáforas 3 e 4 são mais específicas, haja vista que os participantes especificam o meio pelo qual eles seriam capazes de se locomover: um ônibus. É interessante atentar que os participantes ressaltam que a aprendizagem online é como andar na "janela" do ônibus - lugar geralmente preferido nesse meio de transporte.

Nas expressões 5 e 6, é possível perceber um enfoque na multiplicidade de ações simultâneas. Esses aprendizes comparam metaforicamente a aprendizagem à distância com estar em dois lugares distintos ao mesmo tempo. Dessa forma, parece haver um abalo não somente na noção espacial e também na temporal, o que pode ser resultado da experiência desses participantes na aprendizagem pela Internet - espaço onde as ações são rápidas e onde várias ações aconteçam simultaneamente.

Em expressões como a 7 e 8 , é possível perceber o destaque na característica autônoma dessa modalidade de aprendizagem, visto que a aprendizagem é realizada "quando (o aprendiz) quiser e quando puder". Destaco, na metáfora 8, a mesclagem com o transporte a cavalo por meio do uso da expressão "tomar as rédeas", utilizada para se referir ao controle de situações.

A segunda categoria retoma um domínio já apresentado aqui: o domínio VIAGEM. Dezesseis por cento das expressões regulares destacam a trajetória de aprender, o(s) caminho(s), o(s) destino(s), as barreiras e obstáculos dessa viagem. Nessas metáforas, os aprendizes destacam outros elementos de uma viagem como, por exemplo, mapa, fronteira e atalho. As expressões desta categoria seguem no quadro abaixo. 


\begin{tabular}{|c|}
\hline APRENDER INGLÊS À DISTÂNCIA É COMO VIAJAR - 16\% \\
\hline $\begin{array}{l}\text { 1. .. viajar, vc decide onde ir, quantos dias ficar, o que fazer e quando terminar. } \\
\text { (Vy26-HIS) }\end{array}$ \\
\hline 2. ... viajar além de uma fronteira com mapas e um livro guia. (A128-ECV) \\
\hline $\begin{array}{l}\text { 3. ... descobrir o mundo sozinha, ter a oportunidade de errar o caminho e saber que } \\
\text { ninguém vai rir de você, saber que você pode criar estratégias para chegar à } \\
\text { informação que deseja, e que para isso não tem necessidade de manter horários, } \\
\text { nem estar rodeada de outras pessoas. (An46-BIB) }\end{array}$ \\
\hline 4. ... desbravar o caminho para o sucesso bem equipado. (Na21-GEO) \\
\hline $\begin{array}{l}\text { 5. ... superar barreiras, enfrentar muitas dificuldades, ficar muito chateado e } \\
\text { cômodo também. (Di23-MAT) }\end{array}$ \\
\hline 6. ...encurtar o caminho de uma viagem qualquer. (Ra23-ECO) \\
\hline 7. ...encurtar um caminho. (Jo23-ECO) \\
\hline
\end{tabular}

Quadro 3 - Aprender inglês à distância é como viajar

Na expressão 1, a aprendizagem é comparada a uma viagem e destaca a autonomia de uma viagem solitária. Nessa visão, o aprendiz de uma disciplina online seria um viajante que assumiria o controle de sua viagem, estabelecendo seu próprio roteiro, percorrendo o próprio caminho. Já na metáfora 2, o aprendiz seria capaz de ultrapassar fronteiras, ou seja, ultrapassar um limite estabelecido ou imaginado. Além da fronteira metafórica, pode-se perceber a presença de um outro elemento característico de uma viagem: o mapa - instrumento norteador e que permite, entre outras coisas, autonomia na viagem.

A expressão 3 traz claramente o mapeamento de uma viagem. Essa expressão ilustra bem o mapeamento dessa categoria metafórica. Nela, aprendizes seriam viajantes, o processo de aprendizagem à distância seria o caminho, a direção seria o conhecimento da língua e o destino seriam as metas imaginadas por esse grupo de aprendizes: o sucesso, a inclusão no mundo ou mesmo o acesso a informações.

Outro elemento destacado nas metáforas são as barreiras e obstáculos de uma viagem. Nas expressões encontradas, a aprendizagem à distância é percebida como um meio de superar os obstáculos da aprendizagem de uma língua, como pode ser percebido nas expressões 4 e 5. Ademais, a modalidade online é metaforizada como um atalho, um meio de "encurtar" o processo de aprendizagem na língua, como demonstram as expressões 6 e 7.

As duas últimas subcategorias obtiveram a mesma porcentagem $-12 \%$. A terceira subcategoria compreende metáforas que projetam a aprendizagem à distância na aprendizagem da locomoção. Para esse grupo de participantes, aprender inglês online seria como aprender a se locomover. Novamente, percebe-se uma comparação com a infância, período em que geralmente essa habilidade é aprendida. As expressões agrupadas nessa categoria estão reunidas no quadro abaixo. 


\begin{tabular}{|l|l|}
\hline $\begin{array}{l}\text { APRENDER INGLÊ A AISTÂNCIA É COMO APRENDER A SE } \\
\text { LOCOMOVER - 12\% }\end{array}$ \\
\hline 1. ... dar os primeiros passos de um bebê, desvinculados dos olhos cuidadosos e \\
atentos dos pais que as vezes por excesso de zelo nos impede de caminhar \\
sozinhos e fazer nossas próprias escolhas. (P23-MaED) \\
2. ... aprender a andar. Continua dependendo do próprio esforço, mas com \\
algumas facilidades, tais como o horário e o ritmo que se deseja. (Ru53-ETC) \\
3. ... aprender a andar. Apesar de todos quererem nos ajudar somente nós, por \\
esforço próprio, podemos efetivar o nosso desejo. (Pe20-MED) \\
\hline 4. ... um empurrãozinho que nossa mãe nos dá quando estamos aprendendo a \\
andar de bicicleta. O curso à distância tem me dado uma grande força inicial \\
no inglês. (Ju21-NUT) \\
5. ... aprender a andar de bicicleta. Uma vez que pega o jeito fica muito fácil. \\
(Ge25-EMC)
\end{tabular}

Quadro 4 - Aprender inglês à distância é como aprender a se locomover

Nas expressões 1, 2 e 3, aprender inglês à distância é metaforicamente visto como aprender a andar. Além de partilharem um destaque no período infantil, como já visto na primeira parte dessa seção, as três expressões destacam a autonomia exigida para se aprender a andar. Nessa perspectiva, na modalidade online, os estudantes devem ser capazes de aprender sozinhos, "desvinculados dos olhos atentos dos pais" e dependendo do "próprio esforço". Mais uma vez, a autonomia é destacada num mapeamento metafórico sobre a aprendizagem à distância. Já as expressões 4 e 5 possuem um domínio diferente, o de aprender a andar de bicicleta - atividade geralmente aprendida também na infância.

Novamente, a aprendizagem à distância é comparada metaforicamente a uma atividade autônoma que exige esforço do aprendiz. Ao aprender a língua, o estudante se tornaria capaz de se locomover, seja andando, pedalando, ou até mesmo voando, como pode ser evidenciado pela última subcategoria APRENDER INGLÊS À DISTÂNCIA É COMO VOAR. Doze por cento das expressões regulares metaforizaram a aprendizagem à uma locomoção caracterizada pela rapidez, como pode ser percebido no quadro abaixo.

\footnotetext{
APRENDER INGLÊS Å DISTÂNCIA É COMO VOAR - 12\%

1. ... ser um pássaro livre, que voa quando quer. (Lu24-ADM)

2. ... ter asas abertas para gerenciar e coordenar o meu processo de aprendizado. (A122-NUT)

3. ... ser levada pelo vento a lugares desconhecidos. (Ba26-GSS)

4. ... ter um novo meio de aprender sem constrangimento e com a segurança de arriscar novos "voôs". (Re24-EMC)

5. ... voar sem um avião. (Gu21-CCO)
} 
Quadro 5 - Aprender inglês à distância é como voar

Nessa categoria, a autonomia é novamente um elemento em destaque (expressões 1 e 2). Já na metáfora 3, é possível perceber um tipo diferente de voo, um voo involuntário em que o aprendiz (o voador) não sabe bem o destino de sua viagem. Nessas expressões, a rapidez característica da aprendizagem mediada pelo computador é posta em destaque, ou seja, com um processo mais rápido, a aprendizagem é comparada com o ato de voar. Na expressão 5, é possível perceber ainda o elemento contrafactual de voar sem um avião.

A próxima categoria a ser apresentada representa $16 \%$ das metáforas significativamente regulares. Na categoria APRENDER INGLÊS À DISTÂNCIA É COMO RECEBER ALGO EM CASA, estão presentes expressões que enfatizam a praticidade e a facilidade da aprendizagem à distância, advindas da adição da internet à aprendizagem. Abaixo, estão agrupadas as metáforas dessa categoria.

\section{APRENDER INGLÊS À DISTÂNCIA É COMO RECEBER ALGO EM CASA - $16 \%$ \\ 1. ... pedir uma pizza pelo telefone. (Gu20-EMC) \\ 2. ... comprar uma lâmpada pela Internet. (Ro22-EMC) \\ 3. ... receber conhecimento delivery (Ro25-VET) \\ 4. ... ter uma lata de leite condensado em casa e poder fazer brigadeiro! Ou seja, é algo bom, que pode ser feito em casa, não demanda o esforço de ter que ir a algum outro lugar buscar. (De19-PSI)}

5. ... descobrir um novo mundo sem sair de casa. (De32-BIB)

6. ... o famoso jargão "a montanha vai até Maomé". A graduação nos exige muito tempo devido ao número de matérias cursadas ao mesmo tempo. Ter o privilégio de estudar inglês a qualquer hora e lugar, desde que se tenha um computador, facilita muito a nossa vida. (Ma19-EMI)

Quadro 6 - Aprender inglês à distância é como receber algo em casa

As metáforas desta categoria, além de destacarem a facilidade, comparam a aprendizagem online ao serviço de entrega delivery, conhecido pela sua praticidade e comodidade. Nessa perspectiva a aprendizagem é vista não como processo, mas como produto que chegaria à casa do consumidor (o aprendiz). Esse produto é comparado, por esses participantes, com alguns produtos bastante conhecidos por serem entregues em casa, como pizza e outros produtos comprados pela internet.

Nas metáforas 1 e 2 a aprendizagem à distância é conceituada como delivery, ou entrega em domicílio. Este serviço geralmente é acionado com um pedido pelo telefone ou pela internet e esses são justamente os serviços explícitos nas expressões. Já na expressão 3, o aprendiz expressa literalmente o termo delivery, deixando evidente o mapeamento da aprendizagem online com esse tipo de serviço. É importante observar que nessas três metáforas há um produto que é pedido: na expressão 1 é uma pizza e na 
2 uma lâmpada, o que pode estar relacionado à metáfora do conhecimento como luz. Vale ressaltar que a lâmpada é um símbolo amplamente utilizado em desenhos animados ou sátiras para simbolizar novas ideias.

$\mathrm{Na}$ expressão 4, o próprio aprendiz explica a sua metáfora. Além de enfatizar a praticidade e a comodidade de aprender sem sair de casa, o participante ainda utiliza o elemento "brigadeiro". Vale pensar o porquê do participante ter utilizado esse doce e não qualquer outro alimento. Provavelmente, o aprendiz quis enfatizar o prazer que muitos sentem em comer, e especialmente esse tipo de doce.

Finalmente, na expressão 6 , há uma distorção de uma expressão idiomática bastante popular. A expressão original "Se a montanha não vai a Maomé, Maomé vai a montanha" é utilizada para se referir a situações em que a pessoa deve ir em busca de algo. Nessa metáfora, ao invés de ir em busca de algo - "a montanha vai até Maomé". Nesse sentido, é evidente a mesclagem com espaço de serviço delivery. Nessa integração, aprendizes seriam consumidores e a aprendizagem da língua é vista como um produto, este é visto como positivo por esses participantes.

A última categoria desta parte da análise compreende algumas expressões que, por serem idiomáticas, foram agrupadas e analisadas separadamente. Como afirma Kövecses (2010), o sentido mais preciso da expressão depende do mapeamento conceitual particular que ela possui. É justamente o que ocorre com as expressões encontradas nos dados obtidos e que se encontram no quadro a seguir.

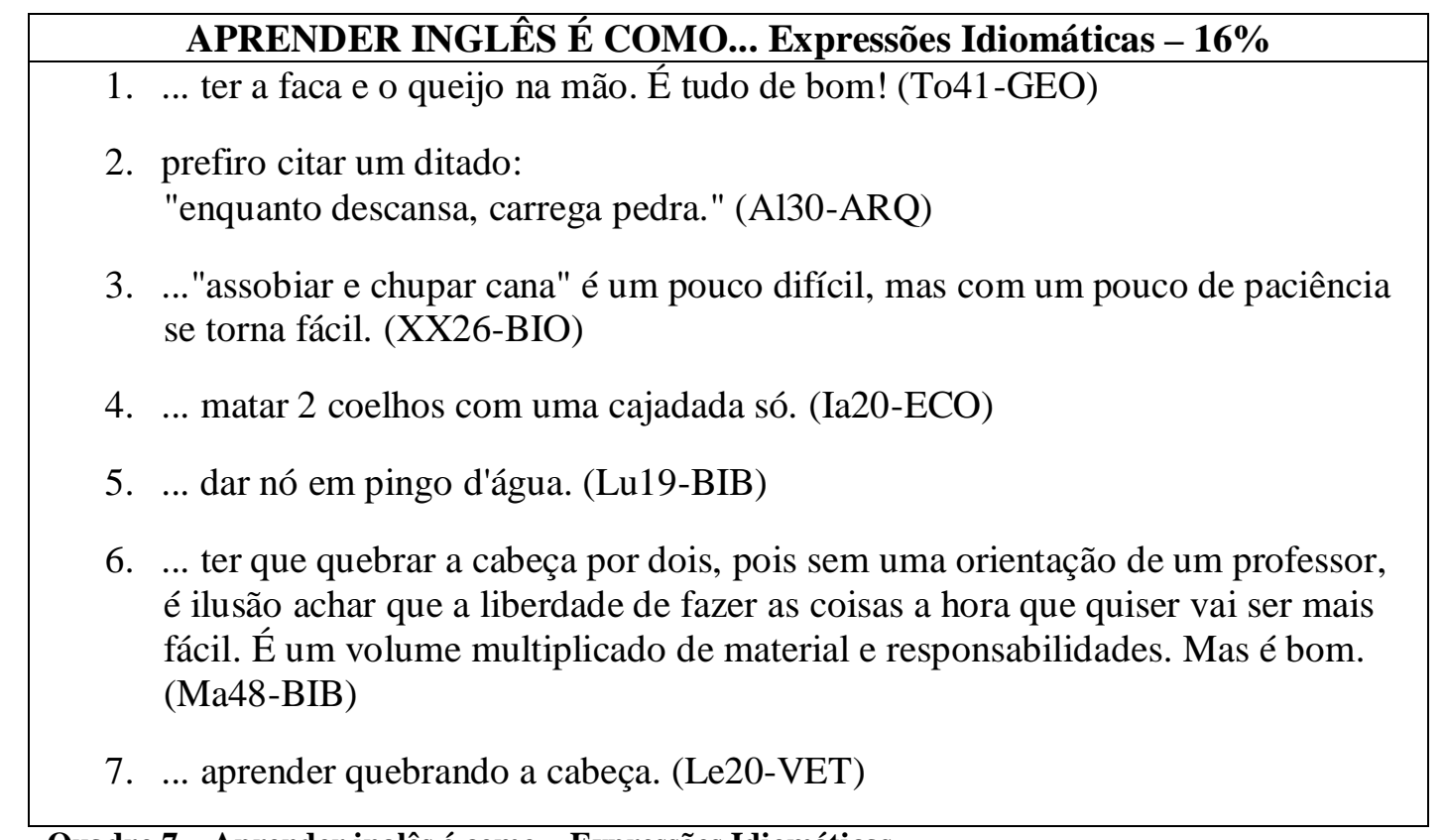

Quadro 7 - Aprender inglês é como... Expressões Idiomáticas

Nas expressões 1, 2, 3 e 4 pode-se perceber uma ênfase na multiplicidade de ações. Nessas expressões, duas ações acontecem ao mesmo tempo. Nesse contexto, a aprendizagem parece ser conceitualizada por meio de uma compressão de ações e tempo, ressaltando, novamente, a praticidade da aprendizagem mediada pelo computador. 
A expressão 5 revela um mapeamento que destaca uma ação impossível. A expressão "dar nó em pingo d'água" é comumente utilizada para se referir a ações praticamente impossíveis de serem feitas e deixa claro o posicionamento do aprendiz sobre esse tipo de aprendizagem.

Já nas expressões 6 e 7 é possível perceber a presença do esquema imagético CONTÊINER, haja vista que para aprender os estudantes deveriam "quebrar a cabeça". Nessa lógica, a aprendizagem ocorreria como o quebrar da cabeça (do contêiner). Só assim os aprendizes conseguiriam deixar a língua entrar dentro desse contêiner.

\section{6) Considerações Finais}

Com base nos dados obtidos, pôde-se perceber que, em geral, a aprendizagem à distância é metaforizada de maneira positiva pelos estudantes investigados. Estes demonstram conceitualizar essa modalidade de ensino como algo inovador, bem como um fator que os traria vantagens sobre os que não "possuem" a língua. Aprender inglês na rede, para o grupo de participantes analisado, pareceu se caracterizar pela compressão ou ressignificação de espaço e tempo

No que se refere à noção de espaço, a língua inglesa parece ser metaforizada como um "acelerador" que permitiria aos aprendizes estar "mais perto" de seus objetivos e a se "locomoverem no espaço". Por ser algo novo, os aprendizes parecem ter de "aprender a se locomover" e embarcar nessa nova "viagem". A metáfora da "viagem" é bem conhecida por conceitualizar a aprendizagem. No entanto, nessa pesquisa, a viagem é um pouco diferente, pois, por ocorrer no ciberespaço, é projetada nos domínios de um "voo".

Sobre à noção de tempo, a metáfora da aprendizagem como voo parece caracterizar bem a ressignificação mencionada anteriormente. A modalidade online parece encurtar a duração do processo, além de propiciar também um caráter autônomo, haja vista que o "voo" é conceitualizado como "livre", podendo ser "coordenado" ou "gerenciado" pelos próprios aprendizes.

Por fim, a aprendizagem online foi metaforizada nos domínios de entregas (delivery), o que evidencia a conceitualização da aprendizagem como um produto e destaca, mais uma vez, a praticidade atribuída aos ambientes virtuais. Isso também foi percebido nas expressões idiomáticas encontradas, que evidenciaram também a compressão dos limites de espaço e tempo, ou seja, a possibilidade de se fazer duas ações ao mesmo tempo.

\section{Referências Bibliográficas}

BERBER SARDINHA, T. Metáfora. São Paulo : Parábola Editorial, 2007.

BLOCK, D. Metaphors we teach and learn by. Prospect, v.7, n.3, 1992, p. 42-5.

CAMERON, L. LOW, G. (Orgs.) Researching and Applying Metaphor. Cambridge : Cambridge University Press, 1999.

COSCARELli, C. V. Entrevista - Uma Conversa com Gilles Fauconnier. Revista Brasileira de Linguística Aplicada. 2005. v.5, n.2, 291-303. 
DÖRNYEI, Z. Research Methods in Applied Linguistics: quantitative, qualitative and mixed methodologies. Oxford, New York: Oxford University Press, 2007.

ELLIS, R. The metaphorical constructions of second language learners. In: BREEN, M. Learner contributions to language learning: new directions in research. Harlow: Pearson Education. 2001, p. 65-85.

FAUCONNIER, G. Mental spaces. Cambridge: Cambridge University Press, 1994.

\begin{tabular}{lcccc} 
& Conceitual Integration. In.: Emergence and Development of Embodied \\
\hline Cognition & (EDEC & 2001). & Disponível & em:
\end{tabular}
http://www.ifi.uzh.ch/ailab/people/lunga/Conferences/EDEC2/edec-proceedings.pdf. Acesso em: 30 set 2009.

; TURNER, M. Conceitual Integration Networks. Cognitive Science. Cognitive Science Society, 1998. Vol. 22, 133-187.

The Way we Think: conceitual blending and the mind's hidden complexities. New York: Basic Books, 2002.

FERRARI, L. V. A Linguística Cognitiva e o Realismo Corporificado: Implicações Psicológias e Filosóficas. VEREDAS, v. 5. nº 2: 23-29, Juiz de Fora, UFJF, 2001.

GRADY, J. E. OAKLEY, T. COULSON, S. Blending and metaphor. In: STEEN, G.; GIBBS, R. (Orgs.) Metaphor in cognitive linguistics, Philadelphia: John Benjamins, 1999. Disponível em http://cogweb.ucla.edu/CogSci/Grady_99.html. Acesso em: 30 set 2009 .

HOLIDAY, Adrian. Doing and Writing Qualitative Research. London: Sage, 2002.

JOHNSON, D. Approaches to research in second language learning. New York: Longman, 1992.

The philosophical significance of image schemas. In.: HAMPE, B. (Org.). From perception to meaning. Image schema in Cognitive Linguistics. Berlim/New York: Mouton de Gruyter, 2005.

KÖVECSES, Z. Metaphor: a practical introduction. Oxford: Oxford University Press, 2002.

Press, 2010.

Metaphor: a practical introduction. $2^{\mathrm{a}}$ edição. Oxford: Oxford University

KRAMSCH, C. Metaphor and the Subjective Construction of Beliefs. In: KALAJA, P. BARCELOS, A. M. F. (Org.) Beliefs about SLA: New Research Approaches. Dordrecht : Kluwer Academic Publishers, 2003, p. 109-128. 
LAKOFF, G. Women, Fire, and Dangerous Things. Chicago: University of Chicago. 1987.

The contemporary theory of metaphor. In: ORTONY, A. Metaphor and

thought. Cambridge: Cambridge University Press, 1995. p.202-251. 1980.

; JOHNSON, M. Metaphors we live by. Chicago : Chicago University Press,

Philosophy in the Flesh: The Embodied Mind and its Challenge to Western Thought. New York: Basic Books, 1999.

LAKOFF, G.; TURNER, M. More than cool reason: field guide to poetic metaphor. Chicago: University of Chicago Press, 1989.

PAIVA, V. L. M. O. BRAGA, J. RACILAN, M. CARNEIRO, M. Leitura em inglês na rede: uma customização do projeto INGREDE na UFMG. Disponível em: http://www.veramenezes.com/projingrede.pdf Acesso em: 30 set 2009.

ROCHA, L. F. M. A fala silenciosa reportada: metáfora, metonímia e mesclagem. Linguística (PPGL/UFRJ), Rio de Janeiro, v. 2, p. 23-38, 2006.

SCHRÖDER, U. A. Da Teoria Cognitiva a uma Teoria mais Dinâmica, Cultural e Sociocognitiva da Metáfora. Alfa. São Paulo, 52(1), p.39-56, 2008.

SELIGER, H. e SHOHAMY, E. Second language research methods. Hong Kong: Oxford University Press, 1989.

SWALES, S. From Metaphor to Metalanguage. Forum, Vol. 32, No. 3, 1994. Disponível em: [http://exchanges.state.gov/forum/vols/vol32/no3/p8.htm]. Acesso em: 20 Abr. 2008. 